\title{
Journal of the Ceramic Society of Japan Call for a Guest Editor for the Feature
}

In order to keep up with the latest trends in the rapidly developing specialized fields of ceramics, and with the current issues facing the industry, the Journal of the Ceramic Society of Japan announces the publication of a Feature with an open contribution of papers under the direction of a guest editor. In this Feature, more than 10 original and review papers - all written in English—concerning current and noteworthy topics will be included. To oversee this issue, applications are invited for a guest editor. The entry requirements follow below. We look forward to hearing from you.

1. Send your letter of application for the position of guest editor to the Chairman of the Journal Editorial Committee (E-mail:submit@cersj.org), including your name, job title, contact details (phone number, address, e-mail address), ideas for an overall topic and a summary of the issue, the number of papers you expect to include in the feature, and the issue number of the journal that you would like to publish as your edition.

2. Candidates and their proposed topics will then be reviewed and a decision taken by the Journal Editorial Committee.

3. A call for papers for the chosen topic will be announced in the Journal of the Ceramic Society of Japan and in Ceramics Japan. The editor must complete and publish the issue within a period of eight (8) months from the date of the said announcement.

4. Only original papers and review papers will be accepted for this issue. Examination methods for these papers should comply with our Paper Examination Rules. Methods of proofreading and the examination procedure should be compliant with the additional Bylaw concerning a Feature Edition by a Guest Editor.

5. The guest editor is responsible for the overall editing of the Feature and also for reporting, in writing, to the committee the results of the paper examination, the order of printing of the papers, and other related issues, at a committee meeting to be held two months prior to publication of the Feature, in order to obtain the committee's approval.

6. Papers that are still under examination at the time of the said committee meeting may be published in an ordinary issue.

7. The guest editor is also responsible for submitting a page-length preface for the Journal of the Ceramic Society of Japan. 